\title{
A Voltammetric Nanodiamond-Coated Screen-Printed Immunosensor for The Determination of a Peanut Allergen in Commercial Food Products ${ }^{\dagger}$
}

\author{
André Carvalho, Maria Freitas $\mathbb{B}$, Henri P. A. Nouws * ${ }^{\mathbb{C}}$ and Cristina Delerue-Matos \\ REQUIMTE/LAQV, Instituto Superior de Engenharia do Porto, Instituto Politécnico do Porto, \\ Rua Dr. António Bernardino de Almeida, 431, 4249-015 Porto, Portugal; andcarv16@gmail.com (A.C.); \\ maria.freitas@graq.isep.ipp.pt (M.F.); cmm@isep.ipp.pt (C.D.-M.) \\ * Correspondence: han@isep.ipp.pt \\ + Presented at the 1st International Electronic Conference on Chemical Sensors and Analytical Chemistry, \\ 1-15 July 2021; Available online: https:/ / csac2021.sciforum.net/.
}

check for updates

Citation: Carvalho, A.; Freitas, M.;

Nouws, H.P.A.; Delerue-Matos, C. A Voltammetric Nanodiamond-Coated Screen-Printed Immunosensor for The Determination of a Peanut Allergen in Commercial Food Products. Chem. Proc. 2021, 5, 10. https://doi.org/10.3390/ CSAC2021-10458

Academic Editor: Núria Serrano

Published: 30 June 2021

Publisher's Note: MDPI stays neutral with regard to jurisdictional claims in published maps and institutional affiliations.

Copyright: (C) 2021 by the authors. Licensee MDPI, Basel, Switzerland. This article is an open access article distributed under the terms and conditions of the Creative Commons Attribution (CC BY) license (https:// creativecommons.org/licenses/by/ $4.0 /)$.

\begin{abstract}
A voltammetric immunosensor was developed to quantify a major peanut allergen, Ara h 1 , using screen-printed carbon electrodes (SPCE) as transducers. A sandwich-type immunoassay was performed on nanodiamond-coated SPCEs using an alkaline phosphatase-labeled detection antibody and a mixture containing an enzymatic substrate (3-indoxyl phosphate) and silver nitrate. The immunological interaction was detected through the (linear sweep) voltammetric stripping of the enzymatically deposited silver. The immunosensor's applicability was evaluated by analyzing breakfast cereals, cookies, and energy and cereal bars. Ara h 1 was successfully tracked in these commercial food products.
\end{abstract}

Keywords: peanut allergy; Ara h 1; food allergy; electrochemical immunosensor; screen-printed carbon electrode; nanodiamond

\section{Introduction}

Peanuts are integrated into the Mediterranean dietary pattern, and their consumption has been recommended worldwide. Despite its noteworthy nutritional value, reported cases of peanut allergy have increased, and therefore commercial food tracking is essential since in extreme cases peanut intake causes anaphylaxis [1].

Detection of peanut traces in food samples can be achieved using electrochemical immunosensors that benefit from their advantageous features such as rapid detection and high selectivity and sensitivity [2]. Because SPCEs can be connected to portable devices, they can be used for in situ allergen analysis. Few electrochemical immunosensors were reported for the determination of Ara h 1: a sandwich-type gold nanoparticle-coated SPCE [3], a reagentless label-free single-walled carbon nanotube-based biosensor [4] and an impedimetric immunosensor using a gold electrode functionalized with 11-mercaptoundecanoic acid self-assembled monolayer [5].

Among the distinct carbon-based nanomaterials, nanodiamonds (NDs) have not yet been used in the analysis of allergens. Nevertheless, due to their 3D configuration efficient electrode nanostructuration can improve the analytical signal [6].

The present work reports the development of an electrochemical immunosensor for the analysis of the peanut allergen Ara $\mathrm{h} 1$ using SPCEs/NDs. In a sandwich-type assay, the antibody-antigen interaction was detected through Linear Sweep Voltammetry (LSV).

\section{Materials and Methods \\ 2.1. Materials and Solutions}

Electrochemical measurements were performed using an Autolab PGSTAT101 potentiostat-galvanostat controlled by the NOVA software package v.1.10 (Metrohm Auto- 
lab). Screen-printed carbon electrodes (SPCE, DRP-110) and the connector to interface the electrodes (DRP-CAC) were supplied by Metrohm DropSens.

Albumin from bovine serum (BSA), 3-indoxyl phosphate (3-IP), nanodiamonds (NDs, nanopowder), nitric acid $\left(\mathrm{HNO}_{3}\right)$, streptavidin-alkaline phosphatase (S-AP), silver nitrate and tris(hydroxymethyl)aminomethane (Tris) were purchased from Sigma-Aldrich. The capture antibody (CAb, anti-Ara h 1), purified natural Ara $\mathrm{h} 1$ and the detection antibody (DAb; biotin, anti-Ara h 1 ) were obtained from Indoor Biotechnologies.

Solutions of BSA and CAb were prepared in Tris- $\mathrm{HNO}_{3}(0.1 \mathrm{M}, \mathrm{pH} 7.2$, Tris buffer); Ara h 1, DAb, S-AP solutions were prepared in Tris buffer containing 1.0\% BSA (m/V). The solution containing 3-IP and silver nitrate was prepared in Tris $0.1 \mathrm{M}\left(\mathrm{pH} 9.8+\mathrm{Mg}\left(\mathrm{NO}_{3}\right)_{2}\right.$ $\left.2 \times 10^{-2} \mathrm{M}\right)$. A Tris buffer (0.1 M, pH 8.5) was used to extract Ara $\mathrm{h} 1$ from the food samples. The evaluation of the accuracy of the sensor's results was performed using a commercial ELISA kit (Indoor Biotechnologies).

\subsection{Methods}

The SPCEs were nanostructurated with NDs $(0.10 \mathrm{ng} / \mathrm{mL})$ and the CAb $(10 \mu \mathrm{g} / \mathrm{mL})$ was immobilized overnight. The electrochemical immunoassay consisted of the following incubation steps: (i) Ara h 1 standard solution/food sample extract (30 min); (ii) DAb (250× dilution, $60 \mathrm{~min}$ ); (iii) S-AP (20,000 $\times$ dilution, $30 \mathrm{~min}$ ) and (iv) enzymatic reaction $\left(3\right.$-IP $\left(1.0 \times 10^{-3} \mathrm{M}\right)$ and silver nitrate $\left.\left(4.0 \times 10^{-4} \mathrm{M}\right), 20 \mathrm{~min}\right)$. Washing between the incubation steps was performed using Tris buffer. The electrochemical analysis of the deposited silver was carried out by Linear Sweep Voltammetry (LSV; voltammograms were recorded using the following parameters: potential range from -0.03 to $+0.4 \mathrm{~V}$, scan rate: $50 \mathrm{mV} / \mathrm{s}$ ). A schematic representation of the sandwich-type immunosensor is presented in Figure 1a.

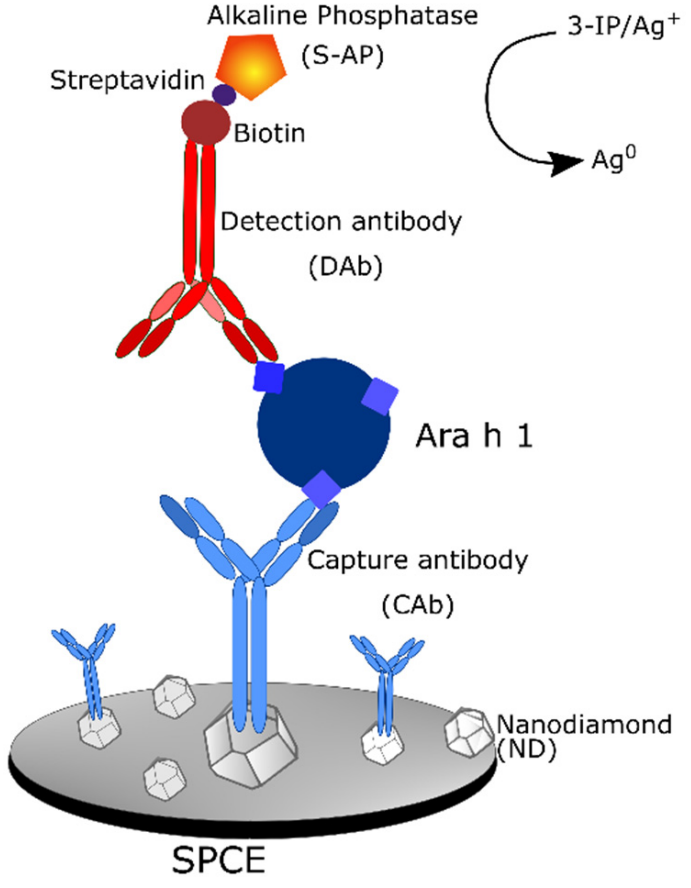

(a)

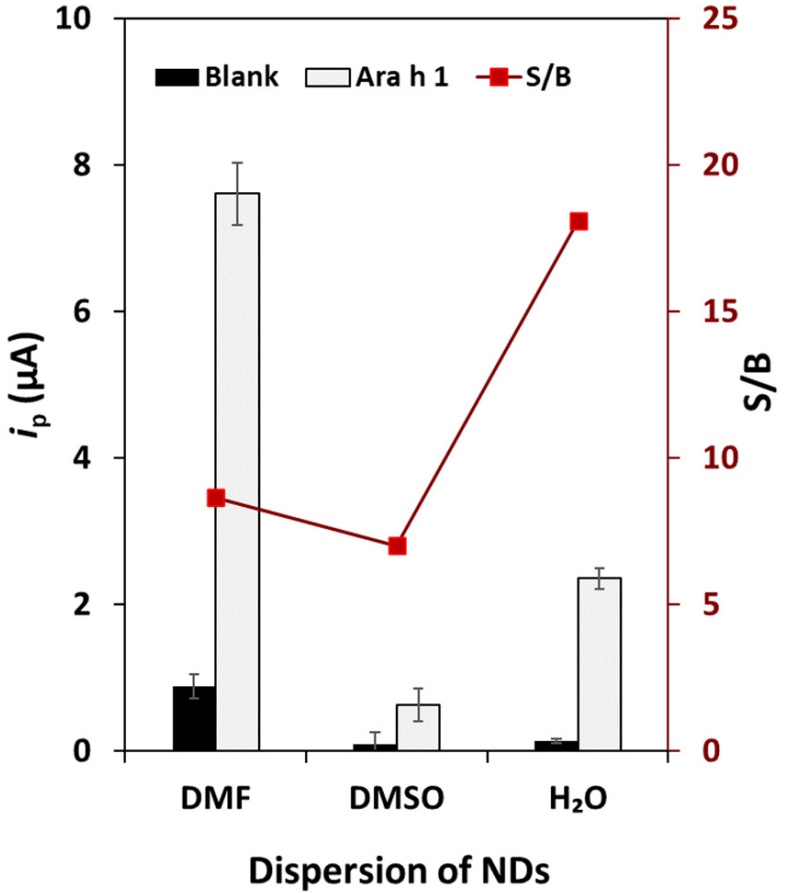

(b)

Figure 1. Nanodiamond-based voltammetric immunosensor. (a) Schematic representation of the immunosensor construction; (b) results obtained for NDs $1 \mathrm{mg} / \mathrm{mL}$ dispersed in DMF, DMSO and $\mathrm{H}_{2} \mathrm{O}$. Experimental parameters: CAb $10 \mu \mathrm{g} / \mathrm{mL}$, Ara h $1(0$ and $250 \mathrm{ng} / \mathrm{mL}), \mathrm{DAb} 250 \times$ dilution, S-AP 200,000 $\times$ dilution, 3-IP $\left(1.0 \times 10^{-3} \mathrm{M}\right), \mathrm{Ag}^{+}\left(4.0 \times 10^{-4} \mathrm{M}\right)$.

A set of food products was bought in local supermarkets. The extraction procedure was performed as recommended by the Ara $\mathrm{h} 1$ standard supplier. Briefly, $1 \mathrm{~g}$ of the food 
sample was mixed with $10 \mathrm{~mL}$ of the extraction buffer, vortexed for $5 \mathrm{~s}$, incubated for $15 \mathrm{~min}$ at $60^{\circ} \mathrm{C}$, centrifuged at $2500 \mathrm{rpm}$ for $20 \mathrm{~min}$ and stored at $-20^{\circ} \mathrm{C}$ until use.

\section{Results and Discussion}

\subsection{Optimization of the Experimental Parameters}

NDs were used for the SPCE's nanostructuration. Several solvents (DMF, DMSO and $\mathrm{H}_{2} \mathrm{O}$ ) that are typically employed for the dispersion of carbon-based nanomaterials were tested. The obtained $i_{\mathrm{p}}$ values are presented in Figure $1 \mathrm{~b}$, and the signal-to-blank (S/B) ratio in the presence and absence of Ara $\mathrm{h} 1(0$ and $250 \mathrm{ng} / \mathrm{mL})$ was used to select the best solvent. As can be observed, the dispersion of $\mathrm{NDs}$ in $\mathrm{H}_{2} \mathrm{O}$ provided the optimum condition to proceed the studies. Then, several ND concentrations were tested, from 1.0 to $0.03 \mathrm{mg} / \mathrm{mL}$, and the best performance was obtained for $0.10 \mathrm{mg} / \mathrm{mL}$.

The electrode surface was biofunctionalized with $\mathrm{CAb}$ and distinct concentrations between 5.0 and $25 \mu \mathrm{g} / \mathrm{mL}$ were studied. A $10 \mu \mathrm{g} / \mathrm{mL}$ concentration was selected and used to study the adequate $\mathrm{DAb}$ dilution (tested range: from $250 \times$ to $1000 \times$ ). In this case a $250 \times$ dilution was found to provide the best performance.

Additionally, several dilutions of the streptavidin-alkaline phosphatase conjugate (S-AP) were tested, from $100,000 \times$ to $250,000 \times$, and the selected value was $200,000 \times$. To conclude the optimization process and reduce the assay time, the antigen incubation time was tested (30 $\mathrm{min}$ and $60 \mathrm{~min}$ ), and it was verified that a $30 \mathrm{~min}$ incubation allowed the appropriate detection of the allergen.

\subsection{Analytical Performance}

The analytical responses toward different Ara $\mathrm{h} 1$ concentrations using the nanostructured SPCE/NDs were evaluated. A linear concentration range was established between 25.0 and $500 \mathrm{ng} / \mathrm{mL}\left(i_{\mathrm{p}}=(0.027 \pm 0.001)[\right.$ Ara $\left.\mathrm{h} 1]+(1.41 \pm 0.31), \mathrm{r}=0.994, \mathrm{n}=5\right)$ with a sensitivity of $0.342 \mu \mathrm{A} \cdot \mathrm{mL} \cdot \mathrm{ng}^{-1} \cdot \mathrm{cm}^{-2}$. The limits of detection (LOD) and quantification (LOQ) were 0.78 and $2.6 \mathrm{ng} / \mathrm{mL}$, respectively (calculated using the equations: $\mathrm{LOD}=3 \mathrm{~S}_{\text {blank }} / \mathrm{m}$ and $\mathrm{LOQ}=10 \mathrm{~S}_{\text {blank }} / \mathrm{m}$ where $S_{\text {blank }}$ is the standard deviation of the blank signal and $\mathrm{m}$ is the slope of the calibration plot).

\subsection{Precision, Recovery and Stability Studies}

The precision of the results provided by the immunosensor was tested using different electrodes on distinct days. A $250 \mathrm{ng} / \mathrm{mL}$ Ara $\mathrm{h} 1$ solution was analyzed in triplicate and a relative standard deviation (RSD) of $7.3 \%$ was obtained.

To evaluate the accuracy of the results, recovery studies were performed using spiked cookie samples. The result for three replicates of added $250 \mathrm{ng} / \mathrm{mL}$ was found to be $75 \%$.

The storage stability of the optimized SPCE/NDs platform was evaluated during several weeks using 0 and $250 \mathrm{ng} / \mathrm{mL}$ Ara h 1 solutions. It was verified that the sensing phase was stable for up to two weeks.

\subsection{Applicability and Method Validation}

The Ara $\mathrm{h} 1$ content in raw peanuts of unknown variety was quantified. The obtained amount $(4.29 \pm 0.16 \mathrm{mg} / \mathrm{g})$ was in accordance with previously reported results [3].

The immunosensor's applicability was evaluated by analyzing several commercial products: (1) cereal bar (no peanut); (2) energy bar containing peanut; (3) cookie that "may contain peanut"; (4) granola that "may contain peanut"; (5) pineapple cookie containing $8 \%$ of peanut. Examples of the obtained LSV voltammograms are shown in Figure 2a. The results were compared with the ones obtained using a commercial ELISA kit (Figure $2 b$ ). The good correlation indicated the accuracy of the results. The results of these analyses are presented in Table 1. 


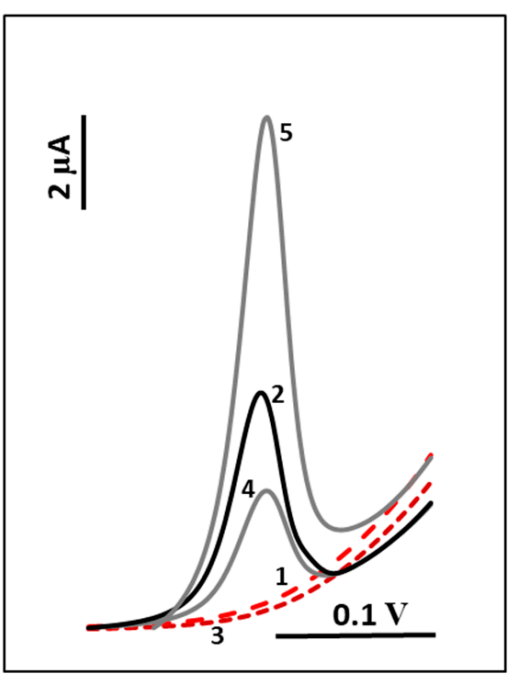

(a)

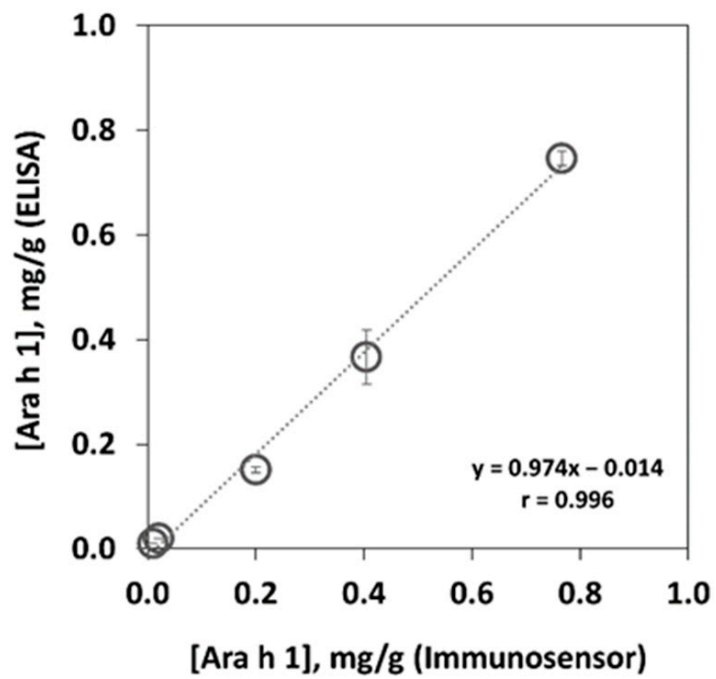

(b)

Figure 2. Analysis of food products. (a) LSV voltammograms (solid lines-presence of Ara h 1; dashed lines-absence of Ara h 1); (b) correlation between the obtained results for the analysis of food products using the developed immunosensor and the commercial ELISA kit. (1) Cereal bar (no peanut); (2) energy bar containing peanut; (3) cookie that "may contain peanut"; (4) granola that "may contain peanut"; (5) pineapple cookie containing $8 \%$ of peanut.

Table 1. Results of the quantification of Ara h $1(\mathrm{mg} / \mathrm{g})$ in food products using an ELISA kit and the developed voltammetric immunosensor.

\begin{tabular}{ccc}
\hline Product & ELISA (mg/g) & Immunosensor (mg/g) \\
\hline Cereal bar (no peanut) & ND & ND \\
Energy bar containing peanut & $0.40 \pm 0.04$ & $0.37 \pm 0.05$ \\
Cookie that "may contain peanut" & ND & ND \\
Granola that "may contain peanut" & $0.20 \pm 0.01$ & $0.15 \pm 0.01$ \\
Pineapple cookie containing 8\% of peanut & $0.77 \pm 0.03$ & $0.75 \pm 0.01$ \\
\hline
\end{tabular}

* ND: not detected.

Ara h 1 was not detected in the (1) cereal bar (no peanut) and the (3) cookie that "may contain peanut". On the latter product's label the warning may intend to protect the producer and consumers due to possible line-production cross-contaminations. On the other hand, the presence of Ara h 1 was confirmed and quantified in the following products: the (2) energy bar containing peanut $(0.37 \pm 0.05 \mathrm{mg} / \mathrm{g}),(4)$ granola that "may contain peanut" $(0.15 \pm 0.01 \mathrm{mg} / \mathrm{g})$ and the (5) pineapple cookie containing $8 \%$ of peanut $(0.75 \pm 0.01 \mathrm{mg} / \mathrm{g})$.

\section{Conclusions}

A nanodiamond-coated SPCE immunosensor was developed to track the major peanut allergen Ara h 1 in commercial food products. Within a total assay time of $2 \mathrm{~h} 20 \mathrm{~min}$, a limit of detection (LOD) of $0.78 \mathrm{ng} / \mathrm{mL}$ was achieved. A set of breakfast products were analyzed and the presence and/or absence of Ara $\mathrm{h} 1$ was confirmed and quantified in the peanut-containing products.

Supplementary Materials: The following are available online at https: / www.mdpi.com/article / 10.3390/CSAC2021-10458/s1. 
Author Contributions: Conceptualization, M.F. and H.P.A.N.; methodology, M.F. and H.P.A.N.; validation, H.P.A.N. and C.D.-M.; formal analysis, M.F. and H.P.A.N.; investigation, A.C. and M.F.; resources, H.P.A.N. and C.D.-M.; data curation, M.F.; writing—original draft preparation, A.C. and M.F.; writing—review and editing, H.P.A.N.; visualization, M.F.; supervision, M.F. and H.P.A.N.; project administration, H.P.A.N.; funding acquisition, H.P.A.N. and C.D.-M. All authors have read and agreed to the published version of the manuscript.

Funding: This research was funded by the European Union (FEDER funds through COMPETE POCI-01-0145-FEDER-030735) and National Funds (Fundação para a Ciência e a Tecnologia) through the project PTDC/QUI-QAN/30735/2017-TracAllerSens-Electrochemical sensors for the detection and quantification of trace amounts of allergens in food products.

Institutional Review Board Statement: Not applicable.

Informed Consent Statement: Not applicable.

Data Availability Statement: Not applicable.

Acknowledgments: This work was also supported by Portuguese national funds (FCT/MCTES, Fundação para a Ciência e a Tecnologia and Ministério da Ciência, Tecnologia e Ensino Superior) through the project UIDB/50006/2020.

Conflicts of Interest: The authors declare no conflict of interest.

\section{References}

1. Lieberman, J.A.; Gupta, R.S.; Knibb, R.C.; Haselkorn, T.; Tilles, S.; Mack, D.P.; Pouessel, G. The global burden of illness of peanut allergy: A comprehensive literature review. Allergy 2021, 76, 1367-1384. [CrossRef] [PubMed]

2. Alves, R.C.; Barroso, M.F.; González-García, M.B.; Oliveira, M.B.; Delerue-Matos, C. New Trends in Food Allergens Detection: Toward Biosensing Strategies. Crit. Rev. Food Sci. Nutr. 2016, 56, 2304-2319. [CrossRef] [PubMed]

3. Alves, R.C.; Pimentel, F.B.; Nouws, H.P.A.; Marques, R.C.B.; González-García, M.B.; Oliveira, M.B.P.P.; Delerue-Matos, C. Detection of Ara h 1 (a major peanut allergen) in food using an electrochemical gold nanoparticle-coated screen-printed immunosensor. Biosens. Bioelectron. 2015, 64, 19-24. [CrossRef] [PubMed]

4. Sobhan, A.; Oh, J.-H.; Park, M.-K.; Kim, S.W.; Park, C.; Lee, J. Single walled carbon nanotube-based biosensor for detection of peanut allergy-inducing protein Ara h 1. Korean J. Chem. Eng. 2018, 35, 172-178. [CrossRef]

5. Huang, Y.; Bell, M.C.; Suni, I.I. Impedance Biosensor for Peanut Protein Ara h 1. Anal. Chem. 2008, 80, 9157-9161. [CrossRef] [PubMed]

6. Gomes, F.; Freitas, M.; Nouws, H.; Morais, S.; Delerue-Matos, C. Graphene as a material for bioelectrochemistry. In Encyclopedia of Interfacial Chemistry Surface Science and Electrochemistry; Wandelt, K., Ed.; Elsevier: Oxford, UK, 2018; pp. 235-240. [CrossRef] 